\title{
Case analysis of novel coronavirus pneumonia in the Second Hospital of Wuhan Iron and Steel Company, Qingshan District, Wuhan, China
}

\author{
Meirong Liu ${ }^{1 \#}$, Yang Lyu ${ }^{2 \#}$, Wenchang $\mathrm{Zhao}^{3}$, Shuang Yu ${ }^{1}$, Dongsheng Shi ${ }^{4,5}$, Wei Lu ${ }^{5,6}$ \\ ${ }^{1}$ Department of Infectious Diseases, Tianjin Hospital, Tianjin, China; ${ }^{2}$ Department of Intensive Care Unit, Tianjin Medical University Cancer \\ Institute and Hospital, National Clinical Research Center for Cancer, Key Laboratory of Cancer Prevention and Therapy, Tianjin's Clinical Research \\ Center for Cancer, Tianjin, China; ${ }^{3}$ Department of Intensive Care Unit, Ninghe District Hospital, Tianjin, China; ${ }^{4}$ Department of Respiratory and \\ Critical Care Medicine, Tianjin Chest Hospital, Tianjin, China; ${ }^{5}$ Tianjin Medical Rescue Team for Hubei, Tianjin, China; ${ }^{6}$ Liver Cancer Center, \\ Tianjin Medical University Cancer Institute and Hospital, National Clinical Research Center for Cancer, Key Laboratory of Cancer Prevention and \\ Therapy, Tianjin's Clinical Research Center for Cancer, Tianjin, China \\ Contributions: (I) Conception and design: M Liu, Y Lyu; (II) Administrative support: D Shi, W Lu; (III) Provision of study materials or patients: M \\ Liu, Y Lyu; (IV) Collection and assembly of data: Y Lyu, W Zhao; (V) Data analysis and interpretation: Y Lyu, S Yu; (VI) Manuscript writing: All \\ authors; (VII) Final approval of manuscript: All authors. \\ \#The authors contributed equally to this work and were co-first authors. \\ Correspondence to: Dongsheng Shi. Department of Respiratory and critical care medicine, Tianjin Chest Hospital, Tianjin 300051, China. Email: \\ shidongsheng2020@163.com; Wei Lu. Liver Cancer Center, Tianjin Medical University Cancer Institute and Hospital, National Clinical Research \\ Center for Cancer, Key Laboratory of Cancer Prevention and Therapy, Tianjin's Clinical Research Center for Cancer, Tianjin 300060, China. \\ Email: luwei1966@126.com.
}

Background: To analyze the clinical and infectious characteristics of new coronavirus pneumonia with diagnosed and suspected cases in the Second Hospital of WISCO(Wuhan Iron and Steel Company) of Qingshan District, Wuhan City, and further enhance the understanding of new coronavirus pneumonia.

Methods: According to the fifth and sixth editions of the new coronavirus pneumonia diagnosis and treatment plan issued by the National Health Commission of the People's Republic of China and National Administration of Traditional Chinese Medicine, we carried out the case analysis and infectious disease investigation and research on the confirmed and suspected cases of new coronavirus pneumonia admitted to the second-floor ward of the hospital from January 28th, 2020, to February 26th, 2020.

Results: From January 28th, 2020 to February 26th, 2020, 83 patients were admitted, 40 were cured, and 7 died. Before February 13th, 69 patients were admitted, including 22 confirmed patients and 47 suspected patients. After February 13th, the data of newly hospitalized suspected patients decreased to 2 people. The average time from onset to diagnosis was 5.38 days. About $57.1 \%$ of the confirmed patients were isolated at home before admission, and $53.2 \%$ of the suspected patients were isolated by hospital observation before admission. The proportion of fever and other clinical symptoms was $81.8 \%, 65.5 \%$ of the patients had the fastest heart rate of 90-120 rpm, and 11 of the patients had severe/critical illness, accounting for $20 \%$. The count of leukocytes, neutrophils, and C-reactive proteins (CRPs) in severe patients was higher than those in light patients $(\mathrm{P}<0.05)$, and the count of lymphocytes was lower than that in mild patients $(\mathrm{P}=0.016)$.

Conclusions: The novel coronavirus pneumonia in Qingshan District of Wuhan in February was diagnosed promptly, controlled, and treated effectively. The combination of traditional Chinese and western medicine in the treatment of new coronavirus pneumonia might help patients.

Keywords: New coronavirus pneumonia; clinical features; infectious diseases

Submitted Jun 09, 2020. Accepted for publication Jul 14, 2020.

doi: 10.21037/apm-20-1372

View this article at: http://dx.doi.org/10.21037/apm-20-1372 


\section{Introduction}

The novel coronavirus infection pneumonia was included in the infectious diseases of class B stipulated in the "Law of the People's Republic of China on prevention and control of infectious diseases" on January 20th, 2020, and the prevention and control measures of class A infectious disease was adopted in the No. 1 announcement of the National Health Commission of the People's Republic of China. Since then, all-round work has been conducted to control the epidemic of new coronavirus pneumonia. The number of patients in Wuhan has increased rapidly, and the epidemic has entered the stage of large-scale transmission (1). Local medical resources are urgent. Besides the blockade of the city, medical workers and medical resources are continuously imported from all over the country, and assisting Wuhan to control epidemic development has also become the top priority. We arrived at Qingshan District, Wuhan, on the night of January 26th, 2020. On January 28th, 2020, we officially took over the ward on the second floor of the Second Hospital of WISCO (specialist hospital for new coronavirus pneumonia), and urgently treated patients with new coronavirus pneumonia. At this time, authoritative reports on the clinical characteristics of new coronavirus pneumonia in Wuhan (2) have been used as a reference. The National Health Commission of the People's Republic of China and the National Administration of Traditional Chinese Medicine issued the 3rd trial version of the new Coronavirus Pneumonia Diagnosis and Treatment (3) as the basis for diagnosis and treatment. Our Tianjin medical team quickly adopted an effective diagnosis and treatment model in the ward following the special local conditions.

Interpersonal transmission has become the main transmission route of COVID-19, and in the process of infecting animals and humans, genetic recombination and mutations will continue to occur, eventually leading to the existence and spread of more virulent and more infectious variants. The main sources of infection for interpersonal transmission are patients diagnosed with COVID-19 and those with latent infection and asymptomatic infection. The main ways of interpersonal communication are droplet transmission, contact transmission, aerosol transmission and other possible transmission ways.

This article introduced the epidemiological characteristics of new coronavirus pneumonia in local areas of Wuhan, described and compared the clinical manifestations, laboratory and imaging tests, treatment differences of patients with several different types of new coronavirus pneumonia in detail, and to provided our diagnosis and treatment experience for the majority of doctors to fight against the epidemic of new coronavirus pneumonia. In particular, we compared the laboratory tests of patients with mild and severe diseases, and the clinical indicators used in the value of new coronavirus pneumonia were studied and discussed and to strengthen the understanding of new coronavirus pneumonia.

We present the following article in accordance with the STROBE reporting checklist (available at http://dx.doi. org/10.21037/apm-20-1372).

\section{Methods}

\section{Object}

From January 28th, 2020 to February 26th, 2020, we collected 83 confirmed cases and suspected cases of new coronavirus pneumonia in the second-floor ward of the Second Hospital of WISCO, 69 cases of cases before February 13thwas selected for statistical analysis of infectious diseases, 55 patients who were in the hospital on February 12 th were selected for clinical symptom statistics. Twenty-seven patients with mild type and 16 patients with severe type were selected from January 28 th to February 26th. All procedures performed in this study involving human participants were in accordance with the Declaration of Helsinki (as revised in 2013). This study was approved by Ethic Committee of Tianjin Hospital (No. 2020-056) and informed consent was taken from all the patients.

Inclusion criteria: (I) patients with confirmed or suspected diagnosis of COVID-19 infection; (II) patients with novel coronavirus pneumonia accepted to treat with informed consent. Exclusion criteria: patients who refuse clinical treatment.

\section{Study method}

The diagnostic and clinical classification criteria of the novel coronavirus pneumonia were on the 4th trial version of the new Coronavirus Pneumonia Diagnosis and Treatment issued by the National Health Commission of the People's Republic of China and National Administration of Traditional Chinese Medicine. 


\section{Diagnostic criteria}

Suspected cases: any 1 in the epidemiological history* + any 2 in the clinical manifestations ${ }^{\#}$; for patients without a clear epidemiological history, 3 of the clinical manifestations need to be met.

Confirmed cases: suspected cases with one of the following etiology evidence: (I) the novel coronavirus nucleic acid was detected positive by real-time fluorescence RT-PCR; (II) viral gene sequencing is highly homologous to known novel coronaviruses.

\section{Clinical type}

Mild: the clinical symptoms are slight, and no pneumonia manifestations are seen on imaging.

Ordinary: with fever, respiratory tract symptoms, imaging showed pneumonia.

Severe: meet any of the following: (I) respiratory distress, $\mathrm{RR} \geq 30$ bpm; (II) blood oxygen saturation $\left(\mathrm{SpO}_{2}\right) \leq 93 \%$ in quiet state; (III) arterial blood oxygen partial pressure $\left(\mathrm{PaO}_{2}\right)$ /oxygen concentration $\left(\mathrm{FiO}_{2}\right) \leq 300 \mathrm{mmHg}(1 \mathrm{mmHg}$ $=0.133 \mathrm{kPa}$ ); (IV) lung imaging showed that the lesions progressed significantly within $24-48$ hours.

Critical: the patient meets one of the following conditions: (I) respiratory failure occurs and requires mechanical ventilation; (II) with shock; (III) combination with other organ failure requires monitoring and treatment in ICU.

\section{Clinical data collection}

The novel coronavirus pneumonia infectious disease card was filled in when patients were admitted to hospital, and the patients' general information, confirmed diagnosis, time, contact history, isolation mode, incidence aggregation, and personnel type were collected. Vital signs, clinical symptoms, laboratory tests, and imaging data were collected during hospitalization. Information needs to be complete, correct, truthful, and reliable.

\section{Statistical analysis}

SPSS20.0 software was used. The measurement data with normal distribution were expressed by "mean \pm standard deviation," and the categorical data were expressed by the number of cases or percentages.

\section{Results}

\section{General information}

From January 28th, 2020 to February 26th, 2020, a total of 83 patients were adults, 40 were discharged from the hospital (48.2\% of the total), and 7 died (8.4\%). Among the discharged patients, 31 were diagnosed, and 9 were suspected; among the dead patients, 4 were diagnosed, and 3 were suspected, all of them were critically ill. A total of 69 patients were admitted before February 13th, 2020. The number of confirmed patients was 22, and the number of suspects was 47 . The number of suspected newly admitted patients after February 13th dropped to 2, and the number of severe and critically ill patients decreased to 0 people after February 20th, 10 were discharged after February 17 th, the number of patients in the hospital decreased significantly. See Figures 1 and 2.

\section{Infectious disease characteristics}

Most of the patients were admitted before February 13th, 2020 , accounting for $83.1 \%(69 / 83)$ of the total number. One of the 69 infectious disease report cards was discarded due to incomplete information, so 68 patients were finally collected. Among the 68 patients, 21 were diagnosed, and 47 were suspected. The age range of the suspected and confirmed patients was mostly $60-69$ years. The average age of the two groups was similar, and there was no statistical difference in gender. The $\mathrm{P}$ value $>0.05$. The time from diagnosis to diagnosis was 5.38 days for confirmed patients and 4.18 days for suspected patients, which had no significant statistical difference and $\mathrm{P}=0.269 .57 .1 \%$ of confirmed patients (12/21 people) were separated at home before admission, and $53.2 \%$ of suspected patients (25/47 people) were separated by hospital observation and isolation before admission. The number of patients contacted with

\footnotetext{
* (I) Travel history or residence history of Wuhan and surrounding areas or other communities with case reports within 14 days before the onset of illness; (II) in contact with the person who has been infected with a new coronavirus (the person who has been tested for nucleic acid) within 14 days before onset; (III) patients with fever or respiratory symptoms from Wuhan and surrounding areas, or from communities with case reports, within 14 days before the onset of illness; (IV) aggressive onset.

" (I) Fever with respiratory symptoms or fever / respiratory symptoms alone; (II) with the imaging characteristics of new coronavirus pneumonia; (III) the number of leukocytes was normal or decreased, and the lymphocyte count was decreased in the early stages of the disease.
} 


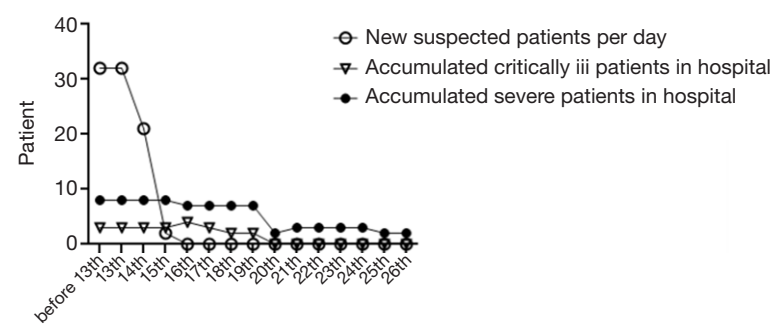

Figure 1 The number of new patients gradually decrease per day. After February 13th, the number of new suspected inpatients dropped to 2, and after February 20th, the number of severe and critically ill patients decreased to 0 .

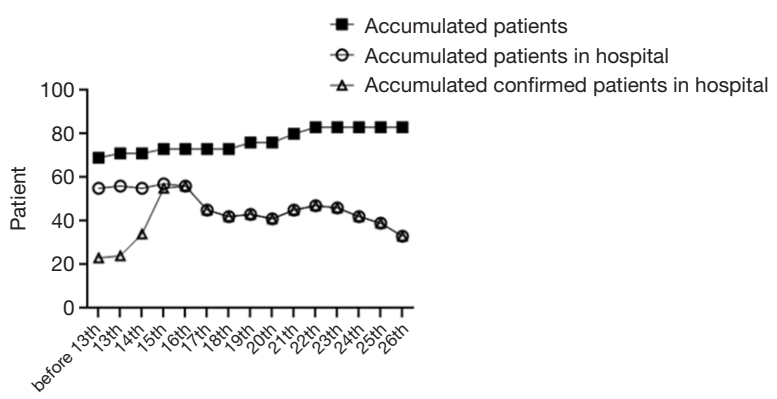

Figure 2 Ten patients were discharged from hospital after February 17th, and the number of patients in hospital decreased significantly, and there was no obvious new suspected cases after February 20th.

confirmed or suspected patients before the onset of disease was 15 ( $71.4 \%$ of the confirmed patients), which was significantly higher than 7 (14.9\% of the suspected, patients) which the statistical difference between the two groups was significant and $\mathrm{P}<0.05$. Forty-two point nine percent of the patients had obvious aggregation, which compared with suspected patients, the difference was statistically significant $(\mathrm{P}<0.05)$. The prevalence rate of medical staff and their families was $11.8 \%(8 / 68)$. See Table 1.

\section{Clinical characteristics}

On February 12th, 2020, 55 patients had been hospitalized, 45 patients were admitted with fever as the primary symptom (accounting for $81.8 \%$ among the total cases), 11 patients $(20 \%$ of the total) suffered from hypoxemia, 36 patients $(65.5 \%)$ had the fastest heart rate of $90-120$ $\mathrm{bpm}$. Also, 36 patients had symptoms of asthenia $(65.5 \%$ of the total cases), 49 cases of loss of appetite (89.1\%), 40 cases
Table 1 Infectious disease characteristics

\begin{tabular}{|c|c|c|c|}
\hline Clinical data & $\begin{array}{c}\text { Confirmed } \\
\text { diagnosis [1] }\end{array}$ & $\begin{array}{c}\text { Suspect } \\
\text { diagnosis [47] }\end{array}$ & $P$ value \\
\hline Age (years) & $58.38 \pm 17.02$ & $58.62 \pm 14.15$ & 0.956 \\
\hline $10-19$ & 1 & 0 & \\
\hline $20-29$ & 1 & 1 & \\
\hline $30-39$ & 2 & 3 & \\
\hline $40-49$ & 1 & 11 & \\
\hline $50-59$ & 3 & 8 & 0.101 \\
\hline $60-69$ & 9 & 11 & \\
\hline $70-79$ & 4 & 10 & \\
\hline$\geq 80$ & 0 & 3 & \\
\hline Gender & & & 0.794 \\
\hline Male & 11 & 27 & \\
\hline Female & 10 & 20 & \\
\hline $\begin{array}{l}\text { Time from onset to } \\
\text { diagnosis (days) }\end{array}$ & $5.38 \pm 4.39$ & $4.18 \pm 2.93$ & 0.269 \\
\hline $\begin{array}{l}\text { History of contact } \\
\text { with confirmed/ } \\
\text { suspected patient } \\
14 \text { days before onset }\end{array}$ & & & $<0.001$ \\
\hline Yes & 15 & 7 & \\
\hline No & 3 & 5 & \\
\hline Unknown & 3 & 35 & \\
\hline Aggregation & & & 0.027 \\
\hline Yes & 9 & 6 & \\
\hline No & 7 & 22 & \\
\hline Unknown & 5 & 19 & \\
\hline $\begin{array}{l}\text { Isolation before } \\
\text { admission }\end{array}$ & & & 0.002 \\
\hline Home & 12 & 12 & \\
\hline Hospital & 5 & 25 & \\
\hline Centralized isolation & 3 & 0 & \\
\hline No isolated & 1 & 8 & \\
\hline Unknown & 0 & 2 & \\
\hline Occupation & & & 0.616 \\
\hline Medical staff & 1 & 5 & \\
\hline $\begin{array}{l}\text { Family members of } \\
\text { medical staff }\end{array}$ & 1 & 1 & \\
\hline Other & 19 & 41 & \\
\hline
\end{tabular}


Table 2 Clinical characteristics of patients admitted

\begin{tabular}{|c|c|c|}
\hline Clinical signs and symptoms & $\begin{array}{c}\text { Number of } \\
\text { cases }\end{array}$ & $\begin{array}{l}\text { Percentage of } \\
\text { total cases (\%) }\end{array}$ \\
\hline \multicolumn{3}{|l|}{ Temperature $\left({ }^{\circ} \mathrm{C}\right)$} \\
\hline$<37$ & 3 & 5.5 \\
\hline $37-38$ & 10 & 18.2 \\
\hline 38-39 & 21 & 38.2 \\
\hline $39-42$ & 14 & 25.5 \\
\hline Unknown & 7 & 12.7 \\
\hline \multicolumn{3}{|l|}{ Clinical symptoms } \\
\hline Fatigue & 36 & 65.5 \\
\hline Loss of appetite & 49 & 89.1 \\
\hline Night sweats & 40 & 72.7 \\
\hline Dry cough & 33 & 60 \\
\hline Diarrhea & 5 & 9.1 \\
\hline \multicolumn{3}{|l|}{ Blood oxygen saturation(\%) } \\
\hline $\mathrm{SpO}_{2}>93 \%$ & 44 & 80 \\
\hline $\mathrm{SpO}_{2} \leq 93 \%$ & 11 & 20 \\
\hline \multicolumn{3}{|l|}{ Maximum heart rate (bpm) } \\
\hline$<60$ & 0 & 0 \\
\hline $60-70$ & 0 & 0 \\
\hline $70-80$ & 5 & 9.1 \\
\hline $80-90$ & 8 & 14.5 \\
\hline $90-100$ & 12 & 21.8 \\
\hline $100-110$ & 13 & 23.6 \\
\hline $110-120$ & 11 & 20 \\
\hline$>120$ & 6 & 10.9 \\
\hline
\end{tabular}

of night sweats (72.7\%), and 33 cases of dry cough (60.0\%). Only 5 patients had symptoms of diarrhea. See Table 2.

\section{Laboratory examination}

The blood routine test and biochemical test results of 43 patients in the hospital in February were analyzed, including 27 cases were mild, and 16 cases were severe. The number of patients with leukocytes ranging from $<4 \times 10^{9} / \mathrm{L}$ in the mild group was higher than the severe group and lower than the severe group for leukocytes $>10 \times 10^{9} / \mathrm{L}$ range. The level of leukocytes in the mild group was lower than the severe group. There was a statistical difference between the two groups and $\mathrm{P}<0.05$. The number of patients with neutrophils with a range of less than $2 \times 10^{9} / \mathrm{L}$ in the mild group was higher than the severe group. It was lower than the severe group with neutrophils ranging greater than $7 \times 10^{9} / \mathrm{L}$. The level of neutrophils in the mild group was lower than that in the severe group with a $\mathrm{P}$ value $<0.001$. The number of patients with lymphocytes ranging less than $1 \times 10^{9} / \mathrm{L}$ in the mild group was lower than the severe group; there was a significantly higher difference compared to the severe group with lymphocytes in the normal range of $1-3.3 \times 10^{9} / \mathrm{L}$. There was a statistical difference between the two groups with the $\mathrm{P}$ value $<0.05$. The mean level of monocytes in the mild group was lower than that in the severe group, and the $\mathrm{P}$ value $=0.01$. There were no significant differences in hemoglobin and platelet indicators between the two groups. Among the biochemical indicators, the average level of total bilirubin in the mild patients' group was lower than that in the severe group. The average levels of serum sodium and serum chlorine in mild patients' groups were higher than those in the severe groups, which had statistical differences. $\mathrm{P}$ value was less than 0.05 , in the range of below $136 \mathrm{mmol} / \mathrm{L}$ of serum sodium, the number of patients in the severe group was higher than that in the mild group, and within the normal range of $136-146 \mathrm{mmol} / \mathrm{L}$, the number of severe patients was lower than that in the mild group, and $\mathrm{P}$ value was less than 0.05 . The number of patients with C-reactive protein (CRP) greater than $10 \mathrm{mg} / \mathrm{L}$ in the severe group is more than that in the mild group, and the number of patients with creatine kinase greater than $174 \mathrm{U} / \mathrm{L}$ in the mild group was more than that in the severe group. There are no significant differences in other biochemical indicators, including liver and kidney function and serum potassium between the two groups. See Table 3.

\section{Image features}

All patients have accepted chest CT examinations. Mild and normal patients showed multiple ground-glass fringing shadows inside and outside the lungs. The lung markings of the lesion could be grid-like, and it could be accompanied by consolidation cord shadow and more than $50 \%$ absorption after one week of treatment. Severe and critically ill patients might have single or multiple groundglass fringing shadows, accompanied by thickening of the lobular septum. Meanwhile, in the progressive stage, the lesions increased, and the scope expanded, and ground-glass 
Table 3 Laboratory examination results

\begin{tabular}{|c|c|c|c|}
\hline $\begin{array}{l}\text { Laboratory } \\
\text { examination }\end{array}$ & $\begin{array}{c}\text { Mild patients } \\
\text { [27] }\end{array}$ & $\begin{array}{c}\text { Severe patient } \\
{[16]}\end{array}$ & $P$ value \\
\hline Leukocyte (×10\%/L) & $5.75 \pm 2.27$ & $9.74 \pm 3.75$ & 0.001 \\
\hline$<4$ & 5 & 0 & \\
\hline $4-10$ & 20 & 11 & 0.039 \\
\hline$>10$ & 2 & 5 & \\
\hline Neutrophil (×10\%/L) & $3.42 \pm 1.52$ & $7.81 \pm 4.06$ & 0.001 \\
\hline$<2$ & 3 & 0 & \\
\hline $2-7$ & 23 & 8 & $<0.001$ \\
\hline$>7$ & 1 & 8 & \\
\hline Lymphocyte $\left(\times 10^{9} / \mathrm{L}\right)$ & $1.77 \pm 0.93$ & $1.22 \pm 0.74$ & 0.051 \\
\hline$<1$ & 3 & 7 & \\
\hline $1-3.3$ & 23 & 9 & 0.042 \\
\hline$>3.3$ & 1 & 0 & \\
\hline Monocyte (×10\%/L) & $0.42 \pm 0.16$ & $0.57 \pm 0.23$ & 0.010 \\
\hline$<0.08$ & 0 & 0 & \\
\hline $0.08-1$ & 27 & 15 & 0.372 \\
\hline$>1$ & 0 & 1 & \\
\hline Hemoglobin (g/L) & $130.74 \pm 14.14$ & $135.19 \pm 17.29$ & 0.364 \\
\hline$<110$ & 2 & 2 & \\
\hline $110-150$ & 24 & 11 & 0.199 \\
\hline$>150$ & 1 & 3 & \\
\hline Platelet $\left(\times 10^{9} / \mathrm{L}\right)$ & $257.78 \pm 83.80$ & $274.31 \pm 109.53$ & 0.580 \\
\hline$<100$ & 1 & 1 & \\
\hline $100-300$ & 17 & 9 & 0.876 \\
\hline$>300$ & 9 & 6 & \\
\hline $\begin{array}{l}\text { Total bilirubin } \\
(\mu \mathrm{mol} / \mathrm{L})\end{array}$ & $10.68 \pm 3.87$ & $14.35 \pm 5.44$ & 0.018 \\
\hline$<3.4$ & 0 & 0 & \\
\hline $3.4-21$ & 26 & 12 & 0.082 \\
\hline$>21$ & 0 & 2 & \\
\hline ALT (U/L) & $39.62 \pm 46.09$ & $32.79 \pm 12.29$ & 0.483 \\
\hline$<5$ & 0 & 0 & \\
\hline $5-40$ & 19 & 11 & 0.512 \\
\hline$>40$ & 7 & 3 & \\
\hline
\end{tabular}

Table 3 (continued)
Table 3 (continued)

\begin{tabular}{|c|c|c|c|}
\hline $\begin{array}{l}\text { Laboratory } \\
\text { examination }\end{array}$ & $\begin{array}{c}\text { Mild patients } \\
\text { [27] }\end{array}$ & $\begin{array}{c}\text { Severe patient } \\
{[16]}\end{array}$ & $P$ value \\
\hline AST (U/L) & $25.23 \pm 12.54$ & $32.71 \pm 24.19$ & 0.203 \\
\hline$<8$ & 0 & 0 & \\
\hline $8-40$ & 23 & 11 & 0.391 \\
\hline$>40$ & 3 & 3 & \\
\hline$\gamma-G T(U / L)$ & $58.26 \pm 77.97$ & $54.57 \pm 35.30$ & 0.908 \\
\hline$<11$ & 0 & 0 & \\
\hline $11-50$ & 8 & 3 & 0.599 \\
\hline$>50$ & 4 & 4 & \\
\hline ALP (U/L) & $75.00 \pm 33.53$ & $75.00 \pm 17.44$ & 1.000 \\
\hline$<40$ & 1 & 0 & \\
\hline $40-150$ & 10 & 7 & 0.729 \\
\hline$>150$ & 1 & 0 & \\
\hline Albumin (g/L) & $37.29 \pm 3.34$ & $34.38 \pm 3.85$ & 0.102 \\
\hline$<35$ & 3 & 4 & \\
\hline $35-50$ & 9 & 3 & 0.376 \\
\hline$>50$ & 0 & 0 & \\
\hline Urea nitrogen $(\mathrm{mmol} / \mathrm{L})$ & $4.11 \pm 1.77$ & $4.94 \pm 2.89$ & 0.267 \\
\hline 2.5 & 5 & 1 & \\
\hline $2.5-8.2$ & 20 & 12 & 0.505 \\
\hline$>8.2$ & 1 & 1 & \\
\hline Creatinine $(\mu \mathrm{mol} / \mathrm{L})$ & $77.85 \pm 22.66$ & $64.74 \pm 14.03$ & 0.057 \\
\hline$<59$ & 4 & 5 & \\
\hline $59-105$ & 19 & 9 & 0.213 \\
\hline$>105$ & 3 & 0 & \\
\hline $\begin{array}{l}\text { Serum potassium } \\
(\mathrm{mmol} / \mathrm{L})\end{array}$ & $4.31 \pm 0.48$ & $4.07 \pm 0.52$ & 0.151 \\
\hline$<3.5$ & 2 & 2 & \\
\hline $3.5-5.3$ & 23 & 12 & 0.709 \\
\hline$>5.3$ & 0 & 0 & \\
\hline Serum sodium (mmol/L) & $139.80 \pm 1.67$ & $137.74 \pm 3.11$ & 0.034 \\
\hline$<136$ & 1 & 5 & \\
\hline $136-146$ & 24 & 9 & 0.028 \\
\hline$>146$ & 0 & 0 & \\
\hline
\end{tabular}

Table 3 (continued) 
Table 3 (continued)

\begin{tabular}{|c|c|c|c|}
\hline $\begin{array}{l}\text { Laboratory } \\
\text { examination }\end{array}$ & $\begin{array}{c}\text { Mild patients } \\
\text { [27] }\end{array}$ & $\begin{array}{c}\text { Severe patient } \\
{[16]}\end{array}$ & $P$ value \\
\hline $\begin{array}{l}\text { Serum chlorine } \\
(\mathrm{mmol} / \mathrm{L})\end{array}$ & $102.98 \pm 1.72$ & $101.39 \pm 2.90$ & 0.038 \\
\hline$<96$ & 0 & 0 & \\
\hline $96-108$ & 25 & 14 & 0.578 \\
\hline$>108$ & 0 & 0 & \\
\hline Creatine kinase (U/L) & $62.22 \pm 55.74$ & $42.14 \pm 45.70$ & 0.454 \\
\hline$<38$ & 0 & 6 & \\
\hline $38-174$ & 8 & 1 & 0.004 \\
\hline$>174$ & 1 & 0 & \\
\hline $\begin{array}{l}\text { Lactate } \\
\text { dehydrogenase (U/L) }\end{array}$ & $187.22 \pm 55.56$ & $293.43 \pm 148.49$ & 0.114 \\
\hline$<109$ & 0 & 0 & \\
\hline $109-245$ & 8 & 4 & 0.260 \\
\hline$>245$ & 1 & 3 & \\
\hline $\mathrm{HBDH}(\mathrm{U} / \mathrm{L})$ & $163.00 \pm 51.27$ & $251.14 \pm 129.27$ & 0.130 \\
\hline$<72$ & 0 & 0 & \\
\hline $72-182$ & 6 & 3 & 0.491 \\
\hline$>182$ & 3 & 4 & \\
\hline CRP (mg/L) & $7.20 \pm 14.31$ & $61.83 \pm 88.50$ & 0.154 \\
\hline$<10$ & 20 & 4 & 0.006 \\
\hline$>10$ & 1 & 3 & \\
\hline
\end{tabular}

$\mathrm{P}<0.05$ indicated that the results were statistically different.

fringing shadows and solid shadows co-existed. Further, in critical cases, the diffuse lesions of both lungs might present as "white lung," mainly consolidation shadows, combined with ground-glass fringing shadows, with signs of blood vessels and bronchi inflation. Pleural effusion and lymphadenopathy were rare in all patients, see Figures $S 1$ and 2 .

\section{Treatment}

All patients accepted general treatment: (I) rest in bed and strengthened supportive treatment to ensure adequate intake; pay attention to water and electrolyte balance to maintain internal environment stability; closely monitor vital signs and blood oxygen saturation. (II) Monitor blood routine, urine routine, CRP, biochemical indicators (liver function, myocardial enzymes, renal function, chest imaging. (III) Severe patients should be given effective oxygen therapy in time, including nasal catheters and masks. All patients were treated with a combination of traditional Chinese and western medicine. The oral medications for patients with mild and general types were as follows: Those who have indications for antibiotics use oral cephalosporins or quinolone antibiotics for 5-7 days as appropriate; Abidol $0.2 \mathrm{~g}$ tid (Oral administration for 5-7 days); Lianhua Qingwen $1 \mathrm{bag}$ tid/No.1 Pneumonia Chinese medicine decoction/Huoxiangzhengqi Capsule $1.2 \mathrm{~g}$ bid (for diarrhea); carbocisteine oral solution $10 \mathrm{~mL}$ tid (for cough and sputum); compound methenamin $2^{\#}$ tid (for severe cough); oral and intravenous infusion drugs for severe and partially critically ill patients were as follows: those who have indications for antibiotic application should inject intravenous antibiotics as appropriate for 5-7 days: NS $100 \mathrm{~mL}$ + ambroxol $30 \mathrm{mg}$ iv bid; NS $100 \mathrm{~mL}$ + doxofylline $0.3 \mathrm{~g}$ iv qd; NS $100 \mathrm{~mL}+$ Xuebijing $100 \mathrm{~mL}$ iv bid (5-7 days); methylprednisolone 40-20 mg iv qd (gradually reduced dosage or temporarily used for patients with high fever and dyspnea); abidol 0.2 tid (5-7 days); Lianhua Qingwen $1 \mathrm{bag}$ tid/No.1 Chinese medicine decoction/ Huoxiangzhengqi Capsule $1.2 \mathrm{~g}$ bid and glucose sodium chloride $500 \mathrm{~mL}+$ Vit C 1-2 g iv qd (for patients with diarrhea and difficulty eating and drinking); omeprazole enteric-coated capsule $1^{\#} \mathrm{qd}$ /omeprazole $40 \mathrm{mg}$ iv $\mathrm{qd}$; carmastam $10 \mathrm{~mL}$ tid; compound licorice tablet $2^{\#}$ tid/ compound methenamin $2^{\#}$ tid.

\section{Discussion}

The outbreak of pneumonia in Wuhan City, Hubei Province at the end of 2019 , is a new type of coronavirus pneumonia (NCP-Novel Coronavirus Pneumonia) caused by SARS-CoV-2. The population was generally susceptible, and NCP quickly spread across the country, and the disease was extremely severe, even more severe than the SARS epidemic in 2003 (4,5). When Wuhan was in emergency status, the Tianjin medical team responded quickly. From January 28th, 2020, we formally took over the ward on the second floor of the Second Hospital of WISCO, Qingshan District, Wuhan City, and admitted confirmed diagnosed and suspected patients.

This article summarized the clinical data and infectious 
disease characteristics of patients in this ward by stages. We found that the number of discharged patients in this ward accounted for $48.2 \%$ of the total in January. The death accounted for $8.4 \%$ of the total. The number of severe and critically ill patients accounted for up to $20 \%$ of the total number of hospitalizations on February 12th, and the proportion gradually decreased to $6.1 \%$, like epidemiological statistics (5). The analysis of infectious disease report card data found there was no difference in age and gender between the confirmed and suspected patients. The time from onset to diagnosis was 5.38 days, which was significantly shortened compared with the data (7 days) before January 2nd, 2020 (2). These results were related to the effective control of the Chinese government, the National Health Commission, and the Chinese Center for Disease Control and Prevention of this disease.

The short duration of 4.18 days for suspected patients was related to the failure of some patients to perform nucleic acid testing in time. The contact history of confirmed patients was clear, while those suspected patients were mostly unknown. The aggregation of suspected patients was significantly lower than confirmed patients and on hospital observation and isolation. Statistical analysis found that the prevalence of medical staff and their families was $11.8 \%$, which was related to insufficient initial protective measures. Clinical characteristics statistics found that most patients with novel coronavirus pneumonia have a fever, but also $20 \%$ of patients have no symptoms of fever. The proportion of patients with a severe illness caused by hypoxia is as high as $20 \%$, and it decreases significantly to $4.7 \%$ as continuous treatment. The heart rate of the patient was too fast, and most people's fastest heart rate was between 90-120, bpm considering the hypoxia caused by pneumonia. Viral myocardial damage in some patients was responsible for the heart rate increasing. Besides, most patients have symptoms, including fatigue, loss of appetite, night sweats, and dry cough, and a few patients have diarrhea, like reference statistics $(6,7)$. The results of laboratory tests in patients revealed that leukocytes, neutrophils, monocytes, and CRP in severe patients were higher than those in the mild group, which might be related to combined with a bacterial infection in some severe patients. The lymphocyte level in the severe group was significantly reduced, which considered it was related to the decrease of CD4 T lymphocytes and NK cells caused by the decrease of immune function in patients with coronavirus infection. Some scholars performed $(8,9)$ homology modeling to show that SARS-CoV-2 has a similar receptor binding domain structure as SARS-CoV, suggesting that COVID19 (novel coronavirus) infection might have similar pathogenesis as SARS-CoV-1 infection, so it was like typical laboratory tests of patients with SARS (10). It could be noted that combined bacterial infection or lymphocyte reduction might be a risk factor for the exacerbation of novel coronavirus pneumonia. Serum sodium was significantly reduced in the severe group, which might be related to decreased appetite or diarrhea.

The treatment for patients followed the notice of the Fifth and Sixth Editions of the novel coronavirus pneumonia diagnosis and treatment plan issued by National Health Commission of the People's Republic of China and National Administration of Traditional Chinese Medicine, management of mild and common cases of the novel coronavirus pneumonia, and diagnosis and treatment plan for severe and critical cases (11-14). From February 15th, 2020, 25 patients were treated with No.1 Pneumonia Chinese medicine decoction instead of antiviral therapy by Lian Hua Qing Wen, and the rest of the necessary treatment remained unchanged. The proportion of severe and critically ill patients decreased from $19.3 \%$ to $6.1 \%$ within the next 10 days, and the proportion of patients with fever and fatigue decreased significantly. Previous studies proposed in the "Clinical experience of novel coronavirus pneumonia" by the Provincial Scientific Research Group of the New Coronavirus Infected Pneumonia Prevention and Control Headquarter demonstrates that the combination of traditional Chinese and western medicine treatment can be successful. The study used the No. 1 pneumonia decoction in pneumonia treatment in 53 confirmed cases of novel coronavirus pneumonia. Seventy-one cases of clinical diagnosis, within a total of 124 cases, the total effective rate of participation of traditional Chinese medicine treatment was more than $90 \%$, the effective rate of confirmed cases was $86.8 \%$. The effective rate of clinically diagnosed cases was $93 \%$.

2019 new coronavirus pneumonia is a new disease caused by the COVID-19 virus infection. The virus takes humans as a new host and may mutate to cause the different performance of different individuals. Pathological anatomy shows that lung tissue is the main damaged organ, and the spleen, heart, blood vessels, liver, gallbladder, and kidney may be damaged and degenerated. Therefore, further observation and research are needed. During this period, our medical team treated patients with mild and general types, and the data collection time was short. Thus, there 
might have a sample size deviation. With the update of the diagnosis and treatment plan, the diagnostic standards, treatment plans may also change. So continuously increasing the observation record of clinical samples is what we need to improve in the next step.

\section{Acknowledgments}

Funding: None.

\section{Footnote}

Reporting Checklist: The authors have completed the STROBE reporting checklist. Available at http://dx.doi. org/10.21037/apm-20-1372

Data Sharing Statement: Available at http://dx.doi. org/10.21037/apm-20-1372

Conflicts of Interest: All authors have completed the ICMJE uniform disclosure form (available at http://dx.doi. org/10.21037/apm-20-1372). The authors have no conflicts of interest to declare.

Ethical Statement: The authors are accountable for all aspects of the work in ensuring that questions related to the accuracy or integrity of any part of the work are appropriately investigated and resolved. All procedures performed in this study involving human participants were in accordance with the Declaration of Helsinki (as revised in 2013).This study was approved by Ethic Committee of Tianjin Hospital (No. 2020-056) and informed consent was taken from all the patients.

Open Access Statement: This is an Open Access article distributed in accordance with the Creative Commons Attribution-NonCommercial-NoDerivs 4.0 International License (CC BY-NC-ND 4.0), which permits the noncommercial replication and distribution of the article with the strict proviso that no changes or edits are made and the original work is properly cited (including links to both the formal publication through the relevant DOI and the license). See: https://creativecommons.org/licenses/by-nc-nd/4.0/.

\section{References}

1. Special Expert Group for Control of the Epidemic of
Novel Coronavirus Pneumonia of the Chinese Preventive Medicine Association. An Update on the Epidemiological Characteristics of Novel Coronavirus Pneumonia (COVID-19). Zhonghua Liu Xing Bing Xue Za Zhi 2020;41:139-44.

2. Huang C, Wang Y, Li X, et al. Clinical features of patients infected with 2019 novel coronavirus in Wuhan, China. Lancet 2020;395:497-506.

3. Guidelines on diagnosis and treatment of novel coronavirus pneumonia (Trial third edition). Tianjin Journal of Traditional Chinese Medicine2020;37:1-3.

4. Xu BL, Guan JL, Shu C, et al. Advance in research on COVID-19. Chin J Nosocomiol 2020;30:806-11.

5. Epidemiology Working Group for NCIP Epidemic Response, Chinese Center for Disease Control and Prevention. The Epidemiological Characteristics of an Outbreak of 2019 Novel Coronavirus Diseases (COVID-19) in China. Zhonghua Liu Xing Bing Xue Za Zhi 2020;41:145-51.

6. Zhuang YJ, Chen Z, Li J, et al. Clinical and epidemiological characteristics of 26 patients diagnosed with novel coronavirus pneumonia. Chin J Nosocomiol 2020;30:817-20.

7. Chen L, Liu HG, Liu W, et al. Analysis of Clinical Features of 29 Patients With 2019 Novel Coronavirus Pneumonia. Zhonghua Jie He He Hu Xi Za Zhi 2020;43:203-8.

8. Hamming I, Timens W, Bulthuis ML, et al. Tissue distribution of ACE2 protein, the functional receptor for SARS coronavirus. A first step in understanding SARS pathogenesis. J Pathol 2004;203:631-7.

9. To KF, Lo AW. Exploring the pathogenesis of severe acute respiratory syndrome (SARS): the tissue distribution of the coronavirus (SARS-CoV) and its putative receptor, angiotensin-converting enzyme 2 (ACE2). J Pathol 2004;203:740-3.

10. Drosten C, Günther S, Preiser W, et al. Identification of a novel coronavirus in patients with severe acute respiratory syndrome. N Engl J Med 2003;348:1967-76.

11. Guidelines on diagnosis and treatment of novel coronavirus pneumonia (Trial fifth edition), CJITWM2020;40:136-8.

12. Guidelines on diagnosis and treatment of novel coronavirus pneumonia (Trial sixth edition). Chin J Infect Control 2020;19:192-5.

13. Yang L, Jiang L, Bai Y, et al. Efficient management 
procedures for suspected or mild novel coronavirus pneumonia cases at mobile cabin hospitals. Acta Acad Med Mil Tert 2020:1-3.

Cite this article as: Liu M, Lyu Y, Zhao W, Yu S, Shi D, Lu W. Case analysis of novel coronavirus pneumonia in the Second Hospital of Wuhan Iron and Steel Company, Qingshan District, Wuhan, China. Ann Palliat Med 2020;9(4):2193-2202. doi: 10.21037/apm-20-1372
14. Zhao J. Diagnosis and Treatment Plan for Severe and Critical Novel Coronavirus Pneumonia. Herald of Medicine 2020:1-12. 


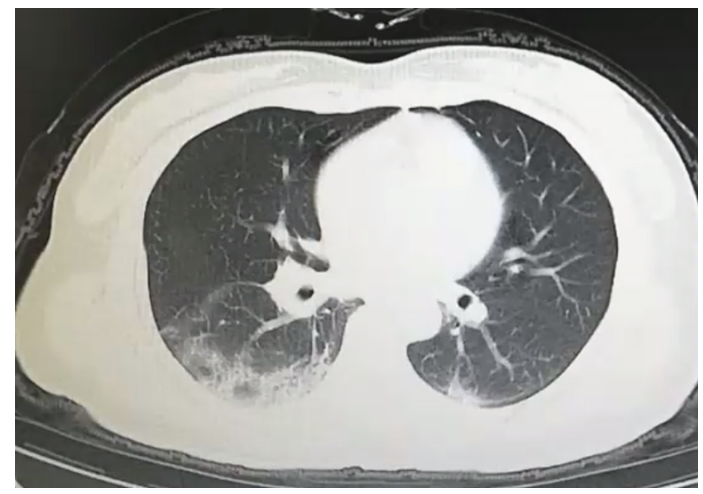

Figure S1 We could see that mild patients showed multiple ground-glass fringing shadows inside and outside the lungs.

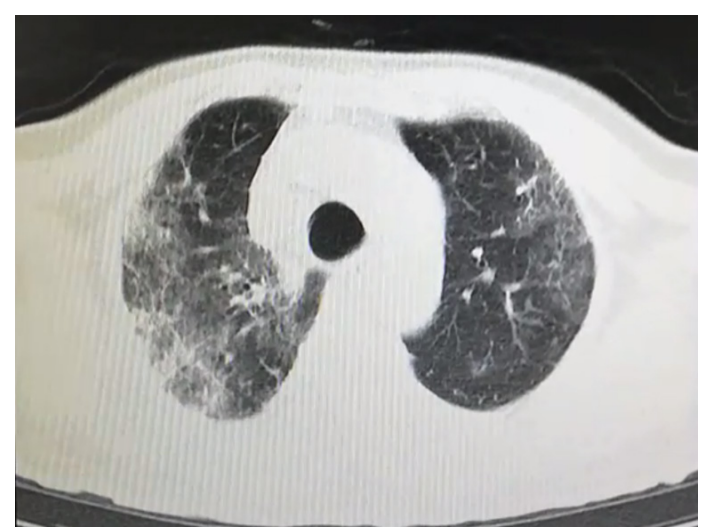

Figure S2 Severe patients might had single or multiple groundglass fringing shadows, accompanied by thickening of the lobular septum. 